\title{
Balancing a multistage vehicle number plate production line using effective cycle time model
}

Stephen C. Nwanya*, Celestine N. Achebe

Department of Mechanical Engineering, University of Nigeria, Nsukka 410001, Nigeria

\section{Article history: \\ Received: March 08, 2020 \\ Revised: May 04, 2020 \\ Accepted: June 07, 2020 \\ Keywords: \\ Effective cycle time \\ Lean philosophy \\ Line balancing \\ Value stream mapping \\ Work content time}

ARTICLE INFORMATION

\section{A B $\quad \mathbf{S}$ T $\mathbf{R}$ A $\mathbf{C}$ T}

Shortest product cycle time is a key criterion for job sequencing and measuring competitiveness among entrepreneurial-based firms. Now, the long waiting time of job orders constitutes a deterministic production line problem in vehicle number plate production plants in Nigeria. Case studies were conducted on those plants, confidentially identified in this paper as A, B, C, and D. Delays caused by nonvalue-adding work processes are major culprits among other contributors to the long queues at these plants. The value stream mapping technique was applied to identify non-value adding activities before the production line was balanced using an effective cycle time model. The index cases to a balanced line, as shown in the results, are increases in process rate by $41 \%, 59 \%, 42 \%$, and $71 \%$ for $\mathrm{A}, \mathrm{B}, \mathrm{C}$, and $\mathrm{D}$, respectively, and overall line efficiency. Next, the system capacities correspondingly increased with the elimination of wastages. These increments imply that bottleneck activities have been minimized, and we have a balanced production line. The devised solution procedure is reliable and recommended to other line manufacturing concerns that experience delays and bottleneck problems.
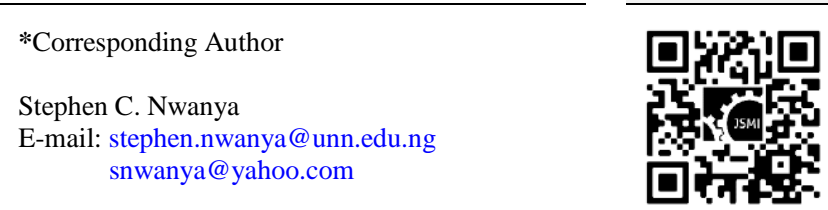

This is an open-access article under the CC-BY-NC-SA license.

\section{INTRODUCTION}

This section discusses the problem of cycle time in relation to line balancing, the contributions to knowledge, and the research gap in the existing knowledge of the subject. Cycle time (CT) is one of the top performance measures widely investigated in literature and practice due to its impact on operations and business [1]. Short cycle time is one of the demands of a multistage lean production system in two folds. Firstly, cycle time is one of the elements of a process design helpful in the allocation of workstations and to determine throughput. Secondly, the shorter is the cycle time, the quicker the time-to-market, and it is considered as a competitive factor in an entrepreneurial-based organization. Thompson [2] asserts that reducing customer waiting time prior to being served is a key performance improvement measure. Cycle time, in the foregoing context, is the time it takes a workstation to produce an item or a service. It includes the preparations for production, average setup, and run time of the workstations. It is also the fastest repeatable time 
by which a workstation processes one part or job arriving to the plant. Hence, it is expressed as time per part or job and does not include losses like breakdowns, defects, and other delays [3]. For a multistage process, it is determined by finding all combinations of the process times in a line. Therefore, if the process rates are increased in one work process or the other, it will in turn results in a reduction of cycle time and a queue, respectively, giving rise to a production line balancing problem. While the aforementioned attributes of cycle time fully describe an appositive business environment in a mass production firm, there are few known applications of it in a unit or entrepreneurial organization, where customers' needs or participation drive the length of the lead time of an item.

In this study, the focus is no more than evaluating process steps and debottlenecking the flow path of job orders in four Nigerian vehicle number plate production plants to ensure value addition. The evaluation of process steps entails the entire line cycle time $\mathrm{x}$-ray to identify delays and other wastes with a view to improving on-time delivery reliability. The case study plants, for the sake of confidentiality, are identified as A, B, C, and D. After evaluation, their productive system as illustrated by the precedence diagram in depicts a multistage situation [4]. It is multistage; when there are several different stages of production requiring different tools and the prior stage (raw material) demand depends on the final stage production [5]. In this situation, the material is converted at stage one into a semi-product (workin-process, WIP) that flows serially, and each plant runs four different single machine work stations until the final product emerges.

Typical operations performed at the four workstations include blanking (BLG), screen printing (SPG), embossing (EBG), and coating/packaging (CPG). Each number plate has to pass through the four workstations in successive steps. Production in the plants is assumed to start once stencil for the preparation of meshes are processed until when the number plates (outputs) are received in the finished goods store. The plants are operated as entrepreneurial organizations.

Unlike mass organizations, entrepreneurial organizations win orders by delivering reliability. In those vehicle number plate production plants, this expectation hardly occurs as long waiting time of job orders constitutes a deterministic production line problem. As a consequence, the workstations face great difficulty and perform their functions with severe obstruction and bottlenecks in the job flow line. This ultimately unbalances the production system, which the plants' management has applied varied strategies for a solution. While the strategies may be promising, we believe insufficient attention was paid to how the organization uses process time. Persistent long queues of job orders can engender customer dissatisfaction and spur product counterfeiting which the effects are hard to quantify in the long run accurately.

From the review of related literature, existing contributions to the knowledge of line balancing are bound. However, expert opinions differ concerning the nature, causes, and effects of production line balancing problems on a production system. Even some experts call for a specific line of action to forestall its recurrence in a system. On nature, Sridhar et al. [6] define line balancing (LB) as a concept of reducing the imbalance between the workers and the workload to achieve desired production rates. This definition is apt and characterizes LB with harmonious load traffic between workstations- a key factor driving a change to lean philosophy (LP). Thus, LB involves performing elemental works on a WIP until it emerges as throughput. LB problems can be categorized into two distinct types: deterministic and probabilistic [7]. The later arises if all input parameters, for example, feed rate, time taken by each resource to complete the task, etc., are uncertain. In this study, the former is the case because the plant parameters are certain (known) and measurable. One of the key factors and performance indicators for the design and balancing of a production line is cycle time [8]. The corollary of this preceding statement is that prudent or otherwise use of cycle time affects line efficiency and ultimately loads flow. Hence, this explains that the distortion of task time is one of the causes of the unbalanced line. A variant of the decision problem being considered is process variability, which has been addressed by Nwanya, et, al. [4]. This previous work on the plants only tried to remove variability. The present study will bring operations of the plants close to lean manufacturing after balancing.

On the part of effects, most of the articles we reviewed treated case studies which can serve as convincing illustrations in that regard. For example, Kusoncum et al. [9] opines that long queues can increase inbound logistics costs. Thus, 
a long queue symptom is an indicator of a process distortion by wastes in a production line.

To eliminate those obstructions and balance the production line, it is necessary we identify the non-value adding activities. Reference Shinde \& More [7] opines that LB is suitable in floworiented production systems for cost-efficient mass production. As a lean system (philosophy) facility layout criteria, LB in the opinions can be a useful tool for improving productivity [10]-[15]. In view of this attribute, appraised lean methods and suggested that they are predisposed to efficiency improvement because of their ability to re-engineer a production flow process [16], [17]. In re-engineering, the production flow, a frequently covered subject in work floor management is work content time (WCT) evaluation. Reference Mishan \& Tap [11] investigated a line balancing problem of bakery industry and represented the unbalanced line causal factors with the Ishikawa diagram. But, what are the specific actions to forestall recurrence?

In the preceding sense, some researchers have advanced various techniques [9], [18]-[24]. Reference MacKay and Steiner [18] opined that processes could be managed using controls that specify mechanisms through which the quality of the product should be monitored, controlled, and verified. They introduced the desensitization of the process in order to reduce variability by making the process more robust to the variability in process input. This is also called parameter design as discussed by Nair et al. [19]. However,
Hopp and Spearman [20] opined that in reducing expected waiting time, the plant managers either must reduce process time (also called cycle time) or reduce variability by pooling resources. Pathway analysis was a model proposed by Katombe and Munapo [21]. Although from literature, the techniques have a lot in common, they are also uniquely different in their applications. The popular tools for identifying sources of waste include time study [11], [23], VSM, simulation, and work sharing methods [22] with VSM more frequently used for deterministic and probabilistic decision problems. With VSM, existing information in a workstation such as the cycle time, uptime or utilization of resources, setup time, WIP inventory, manpower requirement, and the information flow is captured and mapped into the process. The VSM technique has been successfully applied at a university interventional radiology department to eliminate non-value-adding waste in the process of endovascular stent procurement [25]. Also, VSM has proven to be a useful lean technique to minimize the cycle time and increase production [26]. Considering the level of success achieved with VSM in the literature, this paper is motivated to use VSM for the current case study. The application of VSM to uncover non-value adding activities fits a situation where we have inadequate instrumentation apparatus, just like in the plants. For brevity, the consulted relevant literature is further discussed in tabular format, Table 1, after classification according to keywords of the title.

Table 1. Some relevant literature reviewed and classified in accordance with title keywords

\begin{tabular}{|c|c|c|c|c|c|}
\hline Keyword & ECT & $\mathbf{L P}$ & LB & VSM & WCT \\
\hline Article cited & {$[1],[4],[21]$} & $\begin{array}{l}{[9],[11],[14],} \\
{[17],[20]}\end{array}$ & $\begin{array}{l}{[6],[7],[8],} \\
{[10],[12],[14],} \\
{[15],[23]}\end{array}$ & $\begin{array}{ll}{[13],} & {[22],} \\
{[24],} & {[25],} \\
{[26]} & \end{array}$ & [16], [17] \\
\hline $\begin{array}{l}\text { Problem } \\
\text { purpose }\end{array}$ & $\begin{array}{l}\text { Combinations of } \\
\text { task cycle time } \\
\text { plus allowances }\end{array}$ & $\begin{array}{l}\text { Tailored toward } \\
\text { process } \\
\text { improvement }\end{array}$ & $\begin{array}{l}\text { Assigns } \\
\text { elemental task } \\
\text { to workstations }\end{array}$ & $\begin{array}{l}\text { Map input } \\
\text { resources } \\
\text { flows into } \\
\text { process }\end{array}$ & $\begin{array}{l}\text { Re-enginneering } \\
\text { of production } \\
\text { flow in a } \\
\text { workstation for } \\
\text { efficiency } \\
\text { improvement }\end{array}$ \\
\hline Distinction & $\begin{array}{l}\text { Fits into push } \\
\text { operations where } \\
\text { jobs arrive at } \\
\text { random }\end{array}$ & $\begin{array}{ll}\text { Notable } & \text { for } \\
\text { customer } & \\
\text { centered } & \text { and } \\
\text { smooth } & \\
\text { operation } & \end{array}$ & $\begin{array}{l}\text { Optimized } \\
\text { utilization of } \\
\text { manpower and } \\
\text { aquipment }\end{array}$ & $\begin{array}{l}\text { Requires } \\
\text { heuristic } \\
\text { rules instead } \\
\text { of capital } \\
\text { investment }\end{array}$ & $\begin{array}{l}\text { Used in } \\
\text { systematic } \\
\text { operation analysis }\end{array}$ \\
\hline
\end{tabular}


From literature consulted and to the best knowledge of the authors, we declare that the extant literature on manufacturing in Nigeria does not cover LB. Even the available world records few treated entrepreneurial-based firms, and all are outside of African work culture and environment. This recognized research gap is a justification for this study as a measure to close it. The plants are vital national revenue earners, and balancing the production lines will increase their productivity.

This study focuses on reducing idle time in vehicle number production plants. The specific objectives include the identification of non-valueadded processes and the development of an effective cycle time model. The model could help the plant managers combat process redundancy, increase process rate, and reduce queue in the plants.

\section{RESEARCH METHODS}

Rules of improvement with a view to balancing a production line include waiting time reduction, (WTR) queuing model $(\mathrm{Qm})$ and effective cycle time model (ECT). The specific application of each rule, varies with the prevailing decision problem. For example, Qm is mostly used where line balancing of people rather than material or equipment is a priority, such as in banking operations. Here, the description of some dynamics of system performance parameters is required. The WTR is applied to lines that experience heavy load traffic, such as the telecommunication system. The ECT is suitable for product and service design layout, where line efficiency improvement is a priority.

Thus, the latter rule was selected for this study because it supports internal work balance in the plants. Structured questionnaires and personnel interviews with the plant staff were used. The process survey was carried out in the four existing plants. Data from the four case study plants were collected for a set of distinct work elements for the vehicle plate (product), plant-byplant, and processed in a defined order through the workstations. This approach helps in identifying imbalance in utilizing task time and human capital as well as a cause of variance in cycle time.

In applying the ECT method, the study explored the lean philosophy and divided the entire production line according to workstations.
Then, each workstation was analyzed in terms of cycle time, other resources, and layout to unveil counter smooth operation events. VSM was adopted to unveil non-value added activities and then reveal improvement opportunities in all the workstations. Following the guidelines of the VSM, wasteful activities were identified by examining transportation (unnecessary) of material and personnel, inventory, motion, waiting, overproduction, over processing and delays (coined TIMWOOD) in the plants.

From the production cycle efficiency perspectives, the non value added activities identified are:

a. Wait Time: Some co-dependent processes that are not synchronized were identified. For example, the screen printing line waits for blanking operation to end before starting the actual screen printing operation. The plant worker goes to the blanks store to recount the blanks that were initially counted at the blanking line, collect with the necessary documentation, and moves it to the station for SPG. The same screen printed blanks are returned to the stores while the embossing line is waiting. The embossing line in turn goes to the stores to confirm blanks and collects for EBG. It was only between the embossing line and the coating that the embossed plates are immediately passed to the coating line to be coated, and then returned to the store as the finished product. These processes are codependent and needed to be synchronized to gain productive time.

b. Transportation or Movement of Blanks: It was found that blanks move in and out of the store five times during the production time. These blanks are on each occasion recounted by the succeeding line. Manual counting of blanks in the plants is time consuming process.

c. Recounting of Blanks: This is considered as redundant process which adds no value to a product or service. Confirmation of blanks in the nine production hours per day in the plants takes two hours.

d. Defects and over production: Repair or rework of a product or service to fulfill customer requirements. These were found in the BLG and EBG lines due to machine and human errors. However, they are kept under control, especially for the human error, to a maximum limit of $2 \%$ waste of the volume of 
production. Routing machine maintenance takes care of defects emanating from machine faults.

According to Koskela [27] the most important type of waste is at the process or stage wise movement of material and information through the production system. The information from these surveys was used in the calculations that followed from sections 2.1 to 2.7. Finally, we compared production rates, line efficiencies, and cycle times after balancing the line with corresponding current metrics. For clarity, the procedures are structured in a modular framework shown in Fig. 1.

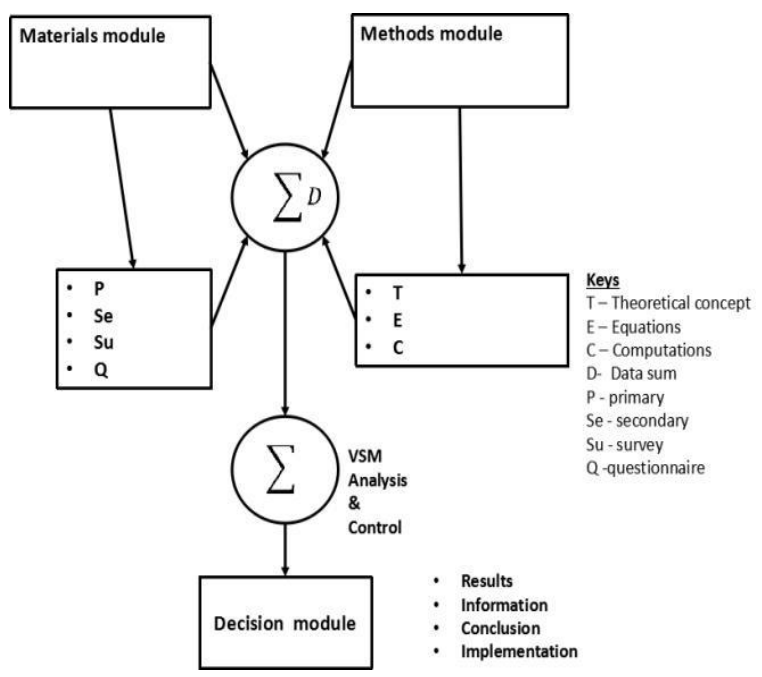

Fig. 1. Modular framework of LB problem solution

\subsection{Calculations: Overall Equipment Effectiveness (OEE)}

OEE is based on three factors, namely availability, performance, and quality.

a. Availability: Measures the time the plant equipment was actually available to run within the specified duration (planned production time) as in "(1)". It accounts for downtime loss.

Availability, $A v=\frac{A O T}{P P T}$

Where: $\mathrm{Av}=$ Availability, $\mathrm{OT}=$ Actual Operating Time, $\mathrm{PPT}=$ Planned Production Time, $\mathrm{AOT}=\mathrm{PPT}-$ Downtime .

b. Performance: Measures how well the plant equipment performed when they are available. It accounts for speed loss as in "(2)," (anything that makes the production process run at less than the maximum possible speed during operation)

Performance, $P=\frac{I C T}{A O T}$

Where: $\mathrm{AOT}=$ Actual Operating Time (Plant "C" runs two shifts $=2 \times$ AOT), $\mathrm{ICT}=$ Ideal Cycle Time (fastest time it will take to produce a pair of numberplate without variability), $\mathrm{TP}=$ Total Production.

c. Quality: measures the percentage of good number of plates on an operational day. Following the Plants' standard, waste was always kept at $2 \%$ or staff be reprimanded. It is expressed as in " 3 ".

Quality, $Q U=\frac{\text { Good number plates produced }}{\text { Total number produced }}$

Equation (4), therefore, measures OEE as: $O E E=A v \times P \times Q U$

\subsection{Capacity measures of the plants}

a. Rated Capacity

Rated capacity of a plant is the planned or engineered rate of output of vehicle number plate under normal or full scale operating conditions. It is derived from product demand $\left(D_{p}\right)$ and measured, for this case study, in pairs of number plates per operational day.

\section{b. Actual System Capacity}

System capacity is the maximum output the system of workers and machines in a plant is capable of producing as an integrated whole. It is the capacity based on the highest production rate established by actual trials. It is measured in pairs of number plates per operational day. Data obtained by direct observation during production hours were compared with data from the research questionnaire, and both tallied.

\section{c. Plant Efficiency}

Plant efficiency (E) measures the level of performance of each plant as a system. Equation (5) shows the evaluation of plant efficiency.

$$
E=\frac{\text { Actual system capacity }}{\text { Rated capacity }} \times 100
$$




\subsection{Production rate of the plants}

The system capacity data collected from the plants was used to evaluate the production (process) rate. Production rate (Rp) as expressed in " 6 " is the average number of jobs (number plates) in pairs that a plant can process per hour. It is also called throughput.

$R_{p}=\frac{\text { Actual system capacity }}{\text { Worked hours per day }}$

Where: $\mathrm{R}_{\mathrm{p}}=$ Production Rate $(\mathrm{pr} / \mathrm{hr})$, worked hours/day $=9$ hours.

$\mathrm{R}_{\mathrm{p}}$ must be converted to a cycle time $\mathrm{T}_{\mathrm{c}}$, which is the time interval at which the line will be operated. The cycle time must take into account the reality that some production time must be lost due to occasional equipment failure, power outages, etc, as a result, line efficiency is less than $100 \%$.

\subsection{Process time of the plants}

It is the average time taken by a production line to process the mean arrivals of jobs in a plant. It includes average setup and run times of the production lines. Process Time (PT) of $\mathrm{n}$ steps in a production line is such that in "7":

$$
P T=\sum_{i=1}^{n}\left(S T_{i}+R T_{i}\right)
$$

Where: PT $=$ Process time, ST $=$ Set-up time, RT: = Run Time (includes infrequent short human and machine errors).

\subsection{Cycle time of the plants}

Cycle time in this work is the time in hours taken by all the production lines in a plant to produce a number plate. Cycle times were evaluated from the process times. Therefore it is the sum of elemental process times of $N$ production lines in a plant, expressed as in " 8 ":

$T_{c}=\sum_{i=1}^{n} P T_{i}$

Where: $\mathrm{T}_{\mathrm{c}}($ mins $/$ cycle $)=$ Cycle time, $\mathrm{PT}(\mathrm{hr})$ $=$ Process time.

However, if line efficiency is known, the cycle time can be evaluated as expressed in (9).
$T_{c}=\frac{60 E}{R_{p}}$

60 convert hourly production rate to cycle time in minutes $\mathrm{E}=$ line efficiency, but production rate is obtained as in " 10 ".

$R_{p}=\frac{D_{p}}{S H D Y}$

$R_{p}=\frac{D_{p}}{50 S H}$

$\mathrm{R}_{\mathrm{p}}=$ average production rate (units $/ \mathrm{hr}$ ), $\mathrm{D}_{\mathrm{p}}=$ annual product demand, $50=$ assume 50 weeks/ year instead of 52 weeks/year, $\mathrm{S}=$ number of shifts / week (shifts / day), $\mathrm{H}=$ number of hours / shift (hrs/shift), D = days / year, Y = years

Cycle time $T_{c}$ establishes the ideal cycle rate for the line in " 11 ".

$R_{c}=\frac{60}{T_{c}}$

$\mathrm{R}_{\mathrm{c}}=$ cycle rate for the line (cycles/hr). $\mathrm{T}_{\mathrm{C}}$ is in $\mathrm{min} /$ cycle.

This rate $R_{c}$ must be greater than the required production rate $R_{p}$ because the line efficiency $E$ is less than $100 \%$. $R_{p}$ and $R_{c}$ are related to $E$ as follows in "12":

$E=\frac{R_{p}}{R_{c}}$

E also implies the proportion of uptime for the line. An assembled product requires a certain total amount of time to build, called the work content time, $\mathrm{T}_{\mathrm{wc}}$. This is the total time of all work elements that must be performed on the line to make one unit of the product. But workload, WL is obtained as the quantity of work units to be produced multiplied by time (hours) required for each work unit as in "13".

$W L=Q T_{c j}$

The time required for each work unit is cycle time on the machine. Where $\mathrm{WL}=$ workload scheduled for a given period ( $\mathrm{hr}$ of work/ $\mathrm{hr}$ or $\mathrm{h}_{\mathrm{T}}$ of work/week), $\mathrm{Q}=$ quantity to be produced during the period (piece (pc)/ hr or pc/week, wk), $\mathrm{T}_{\mathrm{cj}}=$ cycle time required / piece $(\mathrm{hr} / \mathrm{pc})$, if the workload includes multiple parts or product styles 
that can be produced on the same workstation, then "14" is applied.

$$
W L=\sum Q_{j} T_{c j}
$$

$\mathrm{Q}_{\mathrm{j}}=$ quantity of part or product style $\mathrm{j}$ produced during the period $(\mathrm{pc}) \mathrm{j}, \mathrm{T}_{\mathrm{cj}}=$ cycle time of part or product style $\mathrm{j}(\mathrm{hr} / \mathrm{pc})$, and the summation include all of the parts or product to be made during the period. To obtain a number of workstations (n) for the workload, we divide WL by hours available on one station as in " 15 ".

$n=\frac{W L}{A T}$

$\mathrm{AT}=$ available time on one station in the period (hr/period), but the period of interest is $1 \mathrm{hr}$ (60 minutes; $\mathrm{AT}=60 \mathrm{E})$. Thus, "16" holds as:

$T_{w c}=\frac{W L}{R_{p}}$

\subsection{Effective cycle time}

Effective cycle time (ECT) was modeled in this work to synchronize those processes that are co-dependent in the plants to gain time. In this work, ECT is the gain in cycle time when a production line do not wait for its immediate preceding line to completely finish on a job order before it begins process on same job order. Basic assumptions made in applying the ECT include: operation in the plants is serial production and no passing of tasks is allowed (tasks must be processed in the same order on each workstation). A mathematical process for accomplishing effective cycle time model in this work is shown in Table 2.

Table 2. Modeling of effective cycle time for a process flow line in a vehicle number plant

\begin{tabular}{llccc}
\hline $\begin{array}{l}\text { WS1 } \\
\text { (BLG) }\end{array}$ & WS2 & WS3 & WS4 & CT \\
\hline $\mathrm{PT}_{1}$ & $\mathrm{PT}_{2}$ & $\mathrm{PT}_{3}$ & $\mathrm{PT}_{4}$ & $\sum \mathrm{PTi}=\mathrm{CT}$ \\
$\mathrm{PT}_{1}-0$ & $\mathrm{PT}_{2}-\mathrm{t}_{1}$ & $\mathrm{PT}_{3}-\mathrm{t}_{2}$ & $\mathrm{PT}_{4}-$ & \\
$=\mathrm{t}_{1}$ & $=\mathrm{t}_{2}$ & $=\mathrm{t}_{3}$ & $\mathrm{t}_{3}=\mathrm{t}_{4}$ & \\
\multicolumn{1}{c}{$\mathrm{t}_{1}$} & $\mathrm{t}_{2}$ & $\mathrm{t}_{3}$ & $\mathrm{t}_{4}$ & $\sum \mathrm{ti}=\mathrm{ECT}$ \\
\hline
\end{tabular}

Where WS = workstation

\subsection{Process cycle efficiency}

Process cycle efficiency is used in this work to find out how much value each of the processes has added to the customer's expectation. Process cycle efficiency (PCE) is calculated in "17":

$P C E=\frac{\text { Effective cycle time }}{\text { Cycle time }}$

The degree of balance applicable to a line can be determined by the smoothness index (SI). SI indicates the relative smoothness of a given line balance [28] and is expressed in " 18 ".

$$
S I=\sqrt{\sum_{i=1}^{K}\left(P T_{\max }-P T_{i}\right)^{2}}
$$

Where: $\mathrm{PT}_{\max }=\max$ process time, $\mathrm{PT}_{\mathrm{i}}=$ process time of workstation ( $\mathrm{i}$ ), and $\mathrm{K}=$ total number of workstations.

The evaluation of the expected process rate $\left(\mu_{\mathrm{E}}\right)$ was done using " 19 ".

$\mu_{E}=\left[R_{p}\left(\frac{G P T}{C C T}\right)\right]+R_{p}$

Where: $\mu_{\mathrm{E}}=$ Expected Process Rate, $\mathrm{R}_{\mathrm{p}}=$ Production Rate, $\mathrm{CCT}=$ Current Cycle Time, GPT $=$ Gain in production time.

\section{RESULTS AND DISCUSSION}

The observation of the current production parameters of the plants showed that they run a nine hour operation per day, except plant $\mathrm{C}$, which runs two shifts per day. A summary of performance measures in terms of the overall equipment effectiveness and plant efficiency is shown in Table 3. Also, the process and cycle times of the plant workstations are shown in appendices A and B, respectively. Appendix B shows the cycle time in hours for the plants at a growing pace through the production lines. An assessment of table in appendices indicates that the cause of the line balancing problem can be attributed to TIMWOOD constraints. 
Table 3. Overall equipment effectiveness (OEE) and plant efficiency

\begin{tabular}{lccccc}
\hline Plant & Av & P & QU & $\begin{array}{c}\text { OEE } \\
(\%)\end{array}$ & E \\
\hline A & .84 & .95 & .98 & 78 & 28.6 \\
B & .84 & .95 & .98 & 78 & 28.6 \\
C & .85 & .94 & .98 & 78 & 53 \\
D & .85 & .70 & .98 & 58 & 23 \\
\hline
\end{tabular}

Where: $\mathrm{Av}=$ availability, $\mathrm{P}=$ performance, $\mathrm{Qu}=$ quality, $\mathrm{E}=$ efficiency.

The work stations are characterized by unequal cycle times as can be shown in appendix B. Apart from the effective cycle time it was found out that the plants spent about $120 \mathrm{mins}$ in non value added processes. That implies that in the nine hours of operation, the plant works in a day, they spent only seven hours usefully. If these hours are added to the value added process time, there would be gain in the production time as shown in Table 4.

We compared the current cycle time (CCT) with (ECT) in respect of the production rate, and the plot is shown in Fig. 2. Also, a plot of cycle time against the production rate in Fig. 3 shows the effect of reducing cycle time on production.

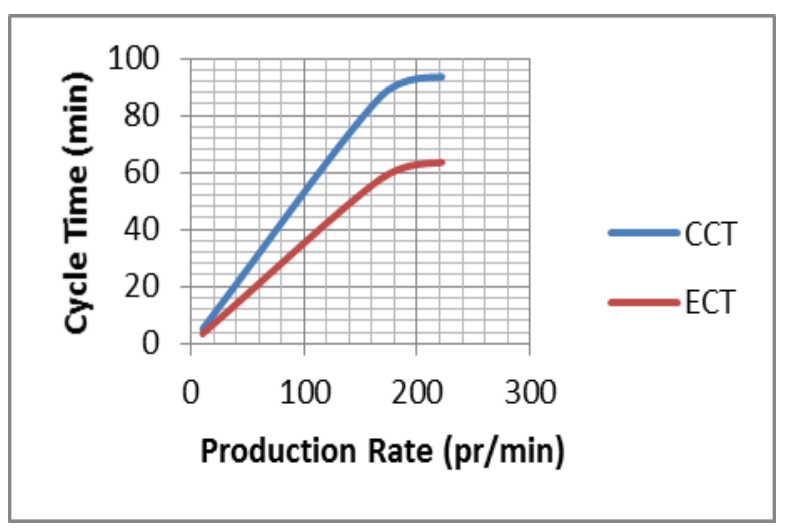

Fig. 2. Increase in Process Rate with ECT

\subsection{Increases in process rate with gain in production time}

The process rates of the plants were reevaluated with the gain in production time, and there was a significant increase in process rate in all the plants. in this evaluation, the results obtained are shown in Table 4.
Table 4. Expected production rate, actual production and efficiency of the plants

\begin{tabular}{lccccccc}
\hline Plant & $\begin{array}{c}\text { CCT } \\
(\mathbf{m i n})\end{array}$ & $\begin{array}{c}\text { ECT } \\
(\mathbf{m i n})\end{array}$ & $\begin{array}{c}\text { GCT } \\
(\mathbf{m i n})\end{array}$ & $\begin{array}{c}\text { GTNV } \\
(\mathbf{m i n})\end{array}$ & $\begin{array}{c}\text { GPT } \\
(\mathbf{m i n})\end{array}$ & $\begin{array}{c}\mathbf{R}_{\mathbf{p}} \\
(\mathbf{p r} / \mathbf{h r})\end{array}$ & $\begin{array}{c}\boldsymbol{\mu}_{\mathrm{E}} \\
(\mathbf{p r} / \mathbf{h r})\end{array}$ \\
\hline A & 109.8 & 74.4 & 35.4 & 120 & 155.4 & 222 & 314 \\
B & 93.6 & 63.6 & 30 & 120 & 150 & 222 & 355 \\
C & 108 & 73.8 & 34.2 & 120 & 154.2 & 444 & 633 \\
D & 86.4 & 57.6 & 28.8 & 120 & 148.8 & 167 & 287 \\
\hline
\end{tabular}

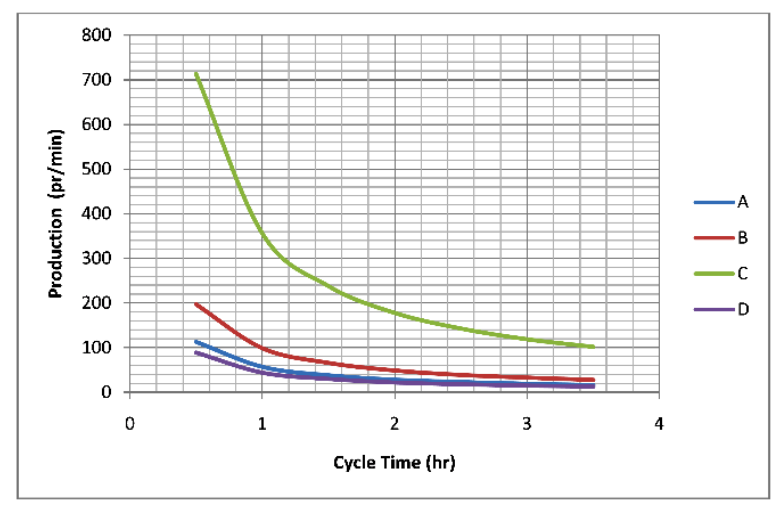

Fig. 3. Effect of reducing cycle time on production

\subsection{Discussion}

This research focused on improving vehicle number plate production line performance by reducing the idle time of the work stations. From the analysis of performance metrics carried out after eliminating non value adding activities, the results showed significant improvement compared with the current performance level. For example, the OEE of the plants was evaluated because it is believed that cycle time could be dragged by the equipment status. The OEE of plants $\mathrm{A}, \mathrm{B}$, and $\mathrm{C}$ were found to be $78 \%$, while plant D was $58 \%$. Each of the plant's efficiency was also evaluated from the capacity measures of the plants. Plants A and B had a plant efficiency of $28.6 \%$. The efficiency of plant $\mathrm{C}$ was $53 \%$ while $\mathrm{D}$ was $23 \%$. The efficiencies of the plants were substantiated from the evaluated process rates of the plants. Plants A and B could process 222prs/hr. Plant C has the process rate of $444 \mathrm{prs} / \mathrm{hr}$ and the plant $\mathrm{D}$ can process $167 \mathrm{prs} / \mathrm{hr}$. These could be why the system capacities were far from the rated capacities after many years of operation.

The cycle times were evaluated from the process times of the production lines and shown in 
appendix A. In the plants 109.8, 93.6, 108, and 86.4 minutes were used by $\mathrm{A}, \mathrm{B}, \mathrm{C}$, and $\mathrm{D}$, respectively for the process mean arrival per job order. These production runs were suspected to be high and inconsistent with the design specification. Since the plants undertake the same job description, the margin of variation in cycle time ought not to be wide.

The minimum cycle times compared with the previous ones (in the current production plan of the plants) were indications of non value added processes engaged by the plants that drag the cycle time. The non value added processes were identified from: wait time, transportation and movement of blanks, recounting of blanks, defects, and overproduction or rework sources. These were time consuming processes. The average time consumed by the non value added processes was estimated to 120 minutes in each of the plants. Therefore, the 9-hour per day is actually reduced to 7 hours after removing non value adding processes.

To further confirm the above, effective cycle time was modeled for the plants to see how the elimination of non value added processes could help the plants to improve performance. The gains in cycle time from the model were $34.4,30,34.2$, and 28.8 minutes respectively for A, B, C, and D plants.

Process cycle efficiency was further used to express how much of the production processes in the plants are value added to the customers. The percentage value added processes in the plant were evaluated to be $67.7 \%, 67.9 \%, 68.3 \%$, and $66.6 \%$ respectively for $\mathrm{A}, \mathrm{B}, \mathrm{C}$, and $\mathrm{D}$ respectively.

Table 4 shows the gain in production time for each of the plants to be $155.4,150,154.2$, and 148.8 minutes for A, B, C, and D Plants, respectively. The gains were used to re-evaluate process rates of the plant using " 10 ". The process rates of the of the plants increased from 222prs $/ \mathrm{hr}$ to $314 \mathrm{prs} / \mathrm{hr}, 222 \mathrm{prs} / \mathrm{hr}$ to $355 \mathrm{prs} / \mathrm{hr}, 444 \mathrm{prs} / \mathrm{hr}$ to 633prs/hr and $167 \mathrm{prs} / \mathrm{hr}$ to $287 \mathrm{prs} / \mathrm{hr}$ for plant A, $\mathrm{B}, \mathrm{C}$ and $\mathrm{D}$ in that order. Also, the system capacities increased from 2,000prs/day to $2,826 \mathrm{prs} /$ day, $2,000 \mathrm{prs} /$ day to $3,195 \mathrm{prs} /$ day, $4,000 \mathrm{prs} /$ day to $5,697 \mathrm{prs} /$ day and $167 \mathrm{prs} /$ day to $2,583 \mathrm{prs} /$ day accordingly for the plants. The same increment applies to the efficiency of the plants which increased from $29 \%$ to $67 \%, 29 \%$ to $74 \%$, $53 \%$ to $79 \%$, and $23 \%$ to $74 \%$ for A, B, C and D plants, respectively. The trend of the behavior of the production line after the balancing process compares with the results achieved by Morshed and Palash [14] which implied high equipment utilization and productivity improvement. These are indications that the plants would be working close to full capacity with the implementation of the effective cycle time model proposed in this research work.

The new production rate would definitely reduce queue length of job orders and unnecessary delays experienced by customers in the plants. The contributions of this work are multifold. The devised approach prepares the work setup for the lean process and deployment of robotics (or creates an inflexible production line). However, the main limitation of an inflexible system, in the worst-case-scenario like lockdown for safety due to a pandemic, is the low ability to allow manipulation in response to sudden demand. This weakness is filled in by employing an adept manager. With a holistic survey conducted on all plants, the managerial team only is required to bring on board intuitive rules that create value for customers.

\section{CONCLUSION}

In this paper, line balancing of a production system for vehicle number plate firms using an effective cycle time model has been carried out. The production lines were characterized by unequal cycle times, which resulted in long queues and delays in the operations. The non value added activities were identified using VSM. Current plant performance was measured by process efficiency calculations. The effective cycle time approach in this work is justified because the case considered involved a deterministic production line problem. Also, it is suitable for a productbased layout of which the case studies were designed to operate. Since the cycle time of an assembly line is predetermined by the desired production rate [15] or throughput, it was less difficult to estimate workstation process time variations.

The objectives of the study were achieved as indicated in the result by a significant gain in production time. This remarkably increased the process rates of the plant. The managerial implications from this research for the plant management are the display of full commitment and involvement of all (managers, employees, and suppliers) to the evolution of lean attributes. This 
is needed in order to reap the benefits of the improved process.

Since the vehicle plates depict security insignia of ownership, future research should consider robotization of the process to minimize non-value added activities introduced by human error. Again, shifts should be deployed in all the plants to enable them to adopt a just-in-time approach to production and accommodate an expected increase in job orders' arrival. It is strongly recommended that the number of plate plants in Nigeria uses the result of this work to improve their performance. If the proposed model is implemented, balancing the production line will increase the ease with which plates are produced. This will be beneficial to national planning as well as improving the mobility of people and goods.

\section{Acknowledgment}

The authors wish to express their profound appreciation to all those who assisted with data for this work. Also, the same gratitude is extended to anonymous reviewers.

\section{REFERENCES}

[1] I. Tirkel, "The effectiveness of variability reduction in decreasing wafer fabrication cycle time," in 2013 Winter Simulations Conference (WSC), Dec. 2013, pp. 37963805, doi: 10.1109/WSC.2013.6721739.

[2] C. Thompson, "Virginia DMV uses simulation to reduce customer wait times." 2018, [Online]. Available: https://www.simul8.com/case-studies.

[3] C. Roser, "How to Measure Cycle Times Part 1." 2015, [Online]. Available: https://www.allaboutlean.com/measurecycle-time-part-1/.

[4] S. C. Nwanya, C. N. Achebe, O. O. Ajayi, and C. A. Mgbemene, "Process variability analysis in make-to-order production systems," Cogent Eng., vol. 3, no. 1, p. 1269382, Dec. 2016, doi: 10.1080/23311916.2016.1269382.

[5] J. O. McClains and L. J. Thomas, Operations Management: production of goods and services. 2nd Edition. New delhi: Prentice-Hall, 2002, available at: Google Scholar.
[6] S. Sridhar and B. Anandaraj, "Balancing of production line in a bearing industry to improve productivity," Hilltop Rev., vol. 9, no. 2, pp. 99-114, 2017, available: https://scholarworks.wmich.edu/hilltoprev iew/vol9/iss2/10/.

[7] A. Shinde and D. More, "Production Line Balancing: Is it a Balanced Act?," Vikalpa J. Decis. Makers, vol. 40, no. 2, pp. 242247, Jun. 2015, doi: $10.1177 / 0256090915590333$.

[8] M. Kamal and J. L. Martinez Lastr, "Assembly Line Balancing and Sequencing," in Assembly Line - Theory and Practice, Waldemar Grzechca, IntechOpen, 2011. available: http://www.intechopen.com/books/assem bly-line-theory-and-practice/assemblyline-balancingand-sequencing.

[9] C. Kusoncum, K. Sethanan, E. P. Putri, and W. Neungmacha, "Simulation-based approaches for processes improvement of a sugar mill yard management system: A case study of the sugar industry in the central region of Thailand," Eng. Appl. Sci. Res., vol. 45, no. 4, pp. 320-331, 2018, available: https://ph01.tcithaijo.org/index.php/easr/article/view/110 192.

[10] D. D. Sheu and J.-Y. Chen, "Line balance analyses for system assembly lines in an electronic plant," Prod. Plan. Control, vol. 19, no. 3, pp. 256-264, Apr. 2008, doi: 10.1080/09537280801966616.

[11] N. N. Mishan and M. M. Tap, "Increasing line efficiency by using timestudy and line balancing in a food manufacturing company," J. Mek., vol. 38, no. 2, pp. 3243, 2015, available: https://jurnalmekanikal.utm.my/index.php /jurnalmekanikal/article/view/22.

[12] N. T. Lam, L. M. Toi, V. T. T. Tuyen, and D. N. Hien, "Lean Line Balancing for an Electronics Assembly Line," Procedia CIRP, vol. 40, pp. 437-442, 2016, doi: 10.1016/j.procir.2016.01.089.

[13] I. Tahir, M. Jahanzaib, A. Wasim, and S. Hussain, "An integrated approach of Value Stream Mapping and simulation for 
process improvements," J. Manuf. Technol. Manag., vol. 20, no. 2, 20115, available:

https://www.researchgate.net/publication/ 276266083_An_Integrated_Approach_of _Value_Stream_Mapping_and_Simulatio n_for_Process_Improvements.

[14] M. N. Morshed and K. S. Palash, "Assembly line balancing to improve productivity using work sharing method in apparel industry," Glob. J. Res. Eng., vol. 14, no. 3, pp. 39-47, 2014, available: http://engineeringresearch.org/index.php/ GJRE/article/view/1136.

[15] W. Grzechca and L. R. Foulds, "The Assembly Line Balancing Problem with Task Splitting: A Case Study," IFACPapersOnLine, vol. 48, no. 3, pp. 20022008, 2015, doi: 10.1016/j.ifacol.2015.06.382.

[16] M. E. Nenni, L. Giustiniano, and L. Pirolo, "Improvement of Manufacturing Operations through a Lean Management Approach: A Case Study in the Pharmaceutical Industry," Int. J. Eng. Bus. Manag., vol. 6, p. 24, Jan. 2014, doi: $10.5772 / 59027$.

[17] A. C. Tsigkas, The Lean Enterprise: from the mass economy to the economy of one. Berlin, Heidelberg: Springer Berlin Heidelberg, 2013, doi: 10.1007/978-3642-29402-0.

[18] R. J. MacKay and S. H. Steiner, "Strategies for variability reduction," Qual. Eng., vol. 10, no. 1, pp. 125-136, Sep. 1997, doi: 10.1080/08982119708919115.

[19] V. N. Nair et al., "Taguchi's Parameter Design: A Panel Discussion," Technometrics, vol. 34, no. 2, pp. 127-161, May 1992, doi: 10.1080/00401706.1992.10484904.

[20] W. J. Hopp and M. L. Spearman, Factory physics. Waveland Press, 2011, available: https://cds.cern.ch/record/2296704.

[21] M. Katombe and E. Munapo, "The quest for process operations variability reduction in manufacturing firms in South Africa," South African J. Econ. Manag. Sci., vol. 19, no. 3, pp. 448-466, 2016, doi: 10.17159/2222-3436/2016/v19n3a10.

[22] M. Parvez, F. Amin, and F. Akter, "Line Balancing Techniques To Improve Productivity Using Work Sharing Method," J. Res. Method Educ., vol. 7, no. 3, pp. 7-14, 2019, available: http://www.iosrjournals.org/iosr-

jrme/papers/Vol-7 Issue-3/Version4/B0703040714.pdf.

[23] M. Mengistu, "Line Balancing Techniques for Productivity Improvement," Int. J. Mech. Ind. Technol., vol. 7, no. 1, pp. 89104, 2019, available: https://www.researchgate.net/publication/ 333310098_Line_Balancing_Techniques_ for_Productivity_Improvement.

[24] A. R. Rahani and M. Al-Ashraf, "Production Flow Analysis through Value Stream Mapping: A Lean Manufacturing Process Case Study," Procedia Eng., vol. 41, pp. 1727-1734, 2012, doi: 10.1016/j.proeng.2012.07.375.

[25] U. K. Teichgräber and M. de Bucourt, "Applying value stream mapping techniques to eliminate non-value-added waste for the procurement of endovascular stents," Eur. J. Radiol., vol. 81, no. 1, pp. e47-e52, Jan. 2012, doi: 10.1016/j.ejrad.2010.12.045.

[26] G. T. . S. Rishi and M. Pramod, "Process improvement in an Industry using Value Stream Mapping Approach," Int. J. Recent Eng. Res. Dev., vol. 3, no. 10, pp. 29-34, 2018, available: http://www.ijrerd.com/papers/v3-i10/6IJRERD-C242.pdf.

[27] L. Koskela, An exploration towards a production theory and its application to construction. VTT Technical Research Centre of Finland, 2000, availabe: https://aaltodoc2.org.aalto.fi/handle/12345 6789/2150.

[28] E. A. Elsayed and T. O. Boucher, Analysis and control of production systems. Prentice Hall, 1994, available: https://infoscience.epfl.ch/record/2350. 
Appendix A: Process time of the plants

\begin{tabular}{|c|c|c|c|c|c|c|c|c|c|c|c|c|}
\hline \multirow{2}{*}{$\begin{array}{l}\text { Plant } \\
\text { Production Lines }\end{array}$} & \multicolumn{3}{|c|}{$\begin{array}{c}\text { A } \\
\text { PT (min.) }\end{array}$} & \multicolumn{3}{|c|}{$\begin{array}{c}\text { B } \\
\text { PT (min.) }\end{array}$} & \multicolumn{3}{|c|}{$\begin{array}{c}\text { C } \\
\text { PT (min.) }\end{array}$} & \multicolumn{3}{|c|}{$\begin{array}{c}\text { D } \\
\text { PT (min.) }\end{array}$} \\
\hline & ST & RT & PT & ST & $\mathrm{RT}$ & PT & ST & $\mathrm{RT}$ & PT & ST & RT & PT \\
\hline Blanking (BLG) & 6 & 6.3 & 12.3 & 6 & 5.6 & 11.6 & 6 & 9.3 & 15.3 & 6 & 4.2 & 10.2 \\
\hline Screen Printing (SPG) & 5 & 47 & 52 & 5 & 44.4 & 49.4 & 5 & 41.8 & 46.8 & 5 & 34.8 & 39.8 \\
\hline Embossing (EBG) & 5 & 17.8 & 22.7 & 5 & 13.3 & 18.3 & 5 & 13.3 & 18.3 & 5 & 13.4 & 18.4 \\
\hline Coating/Packaging & 5 & 17 & 22 & 5 & 9.6 & 14.6 & 5 & 22.2 & 27.2 & 5 & 12.8 & 17.8 \\
\hline
\end{tabular}

Appendix B: Cycle time of the plant workstations

\begin{tabular}{lcccc}
\hline Plants & A & B & C & D \\
Production Lines & CT (hr.) & CT (hr.) & CT (hr.) & CT (hr.) \\
\hline Blanking (BLG) & 0.21 & 0.19 & 0.26 & 0.17 \\
Screen Printing (SPG) & 1.08 & 1.01 & 1.04 & 0.83 \\
Embossing (EBG) & 1.46 & 1.32 & 1.35 & 1.14 \\
Coating/Packaging (CPG) & 1.83 & 1.56 & 1.8 & 1.44 \\
\hline
\end{tabular}

